Preparat i on of si I k resi ns by hot pressing Bonbyx mori and Eri silk powders

\begin{tabular}{|l|l|}
\hline 著者 & $\begin{array}{l}\text { TUAN Hoang Anh, H RAl Shi nj i , TANADA Yasushi , } \\
\text { AKl OKA Shot a }\end{array}$ \\
\hline $\begin{array}{l}\text { j our nal or } \\
\text { publ i cat } \mathrm{i} \text { on } \mathrm{t} \text { i t l e }\end{array}$ & Nat er i al s sci ence \& engi neer i ng. C \\
\hline vol une & 97 \\
\hline page $r$ ange & $431-437$ \\
\hline year & $2019-$ O4 \\
\hline URL & ht t p: //hdl . handl e. net /10258/00009982 \\
\hline
\end{tabular}


Preparation of Silk Resins by Hot Pressing Bombyx mori Silk and Eri Silk Powders

H.A. Tuan ${ }^{a^{*}}$, S. Hirai ${ }^{b^{*}}$, Y. Tamada ${ }^{c}$ and S. Akioka ${ }^{d}$

${ }^{a}$ Graduate Student, Muroran Institute of Technology, Japan

${ }^{b}$ Research Center for Environmentally Friendly Materials Engineering, Muroran Institute of

Technology, 050-8585, 27-1 Mizumoto-cho Muroran-shi Hokkaido, Japan

${ }^{c}$ Faculty of Textile Science and Technology, Shinshu University, 386-8567, 3-15-1 Tokida, Ueda City,

Nagano, Japan

${ }^{d}$ Graduate Student, Muroran Institute of Technology, Japan

*Corresponding author:

Email: hoanganhtuan07@gmail.com

hirai@mmm.muroran-it.ac.jp

\section{Abbreviations $^{1}$}

$\begin{array}{ll}1 \text { SEM } & \text { Scanning electron microscopy } \\ \text { XRD } & \text { X-ray diffraction } \\ \text { FT-IR } & \text { Fourier-transform infrared }\end{array}$




\section{Abstract}

In this study, silk resins were investigated as alternatives to tortoise shell for eyeglass frames and ornaments. Silk resins were prepared by crushing the raw waste of Bombyx mori and Eri silk threads (rather than by scouring and dissolving them) and hot pressing the silk powder in a stainless steel die. The hot pressing was performed at a pressure of $31.2 \mathrm{MPa}$ until the temperature reached a predetermined temperature of $150{ }^{\circ} \mathrm{C}-180^{\circ} \mathrm{C}$. Because B. mori silk powder comprises finer particles than Eri silk powder, the obtained B. mori silk resin was denser than the Eri silk resin over a range of resinification temperatures. The micro-Vickers hardness, three-point bending strength, and elastic modulus of the B. mori resin reached $\mathrm{Hv} 60,112 \mathrm{MPa}$, and $9.1 \mathrm{GPa}$, respectively, after 7 days of drying, whereas those in the Eri silk resin were lower ( $\mathrm{Hv} 55,98 \mathrm{MPa}$, and 8.5 GPa, respectively). These excellent mechanical properties of B. mori silk resin was attributed to its higher apparent density compared with that of Eri silk resin. According to the Fourier-transform infrared spectra, the $\beta$-sheet structure content in the B. mori silk increased while the random coil structure decreased after the resinification and drying; in contrast, the secondary structure in the Eri silk resin was changed from a random coil to $\beta$-strand structure after the resinification process, which was converted to a $\beta$-sheet structure after the drying process. However, the $\beta$-sheet structure content was similar to the Eri silk and the $B$. mori silk following the resinification and the drying, implying that the differences in the mechanical properties are due to the differing densities of the resins. These findings regarding the fabrication of silk resins are likely to contribute to the future development of useful materials with favorable mechanical properties. 
Keywords: Eri silk thread, Bombyx mori silk thread, milling powder, hot pressing, resinification, mechanical properties 


\section{Introduction}

The global output of raw silk is increasing due to the demand from high-income countries.

Although China supplies the largest quantity of raw silk, Vietnam is the world's sixth largest producer of raw silk after India, Uzbekistan, Thailand, and Brazil [1]. Vietnamese silk products are largely obtained from either Bombyx mori silkworms or Eri silkworms. B. mori silkworms generally feed on mulberry leaves, whereas Eri silkworms mostly consume cassava leaves [2]. It is known that cassava is easier to cultivate and is useful for other agricultural purposes (e.g., Cassava roots are used as a food product and for ethanol production). Cassava has six cultivation seasons per year, which dramatically increases its annual productivity of raw cocoons compared with mulberry, which has only has one to two cultivation seasons per year. Because Eri silkworms have superior disease resistance and sericulture does not require special technology, it is feasible to produce large amounts of cocoons from small-scale sericulture, which is largely performed by those in Anh Son district, Nghe An province, Vietnam. However, the large number of tubular holes that exist along the thread length and the short fibers of Eri thread makes mechanical spinning impossible [3].

Silk resin has recently been investigated as an alternative to tortoise shell as a material for eyeglass frames and ornaments. Silk resins can be prepared by hot pressing either silk fibroin sheets [4] or silk powder [5]. Fibroin sheets are formed by dissolving silk thread in a hot aqueous calcium chloride solution containing ethanol, casting the desalinated fibroin solution with glycerol, drying, and washing in water to remove the glycerol; then, 30-100 sheets are stacked while immersed in the fibroin solution and hot pressed under a pressure of $19.6-24.6 \mathrm{MPa}$ at $90{ }^{\circ} \mathrm{C}$. After drying at $90{ }^{\circ} \mathrm{C}$, 
the maximum bending strength of the laminated silk fibroin sheet is comparable with that of tortoise shell. When preparing silk resin from silk powder, the powder is mixed with water and hot pressed between stainless steel plates with a pressure of $30-80 \mathrm{MPa}$ at a predetermined temperature of $100^{\circ} \mathrm{C}-190^{\circ} \mathrm{C}$. Silk resin that was prepared by hot pressing silk powder containing $27 \%$ water under a pressure of $44 \mathrm{MPa}$ at a temperature of $160^{\circ} \mathrm{C}$ for a retention time of $1 \mathrm{~h}$ was shown to possess the same hardness as tortoise shell. However, its bending strength was around $70 \mathrm{MPa}$, which was far short of that of tortoise shell (225-333 MPa).

Our research group introduced a sintering method based on the direct application of a large pulsed electric current to a graphite die [6]. Silk powders loaded onto the graphite die were found to be heated uniformly by internally generated heat due to Joule heating, which occurs when a strong current passes through the contact points between compacted particles. Moreover, the Joule heat can be generated at many points dispersed throughout the sample by repeatedly switching the voltage and current on and off. By this approach, uniform parts can be compacted more quickly than through the use of conventional hot pressing. In the previous study, silk powder was obtained by dissolving scoured silk thread in an aqueous solution of a neutral salt, desalination, and freeze drying; the obtained silk powder was then treated by the proposed pulsed electric current sintering method at a pressure of $20-30 \mathrm{MPa}$ at a temperature of $150{ }^{\circ} \mathrm{C}-170^{\circ} \mathrm{C}$. The results showed that the obtained silk resin possessed a thermal conductivity of $0.44 \mathrm{~W} /\left(\mathrm{m} \cdot{ }^{\circ} \mathrm{C}\right.$ ) (which is extremely high for a resin [7]), a glass transition temperature of $180^{\circ} \mathrm{C}$, a bending strength of $100 \mathrm{MPa}$, and a bending elastic modulus of $4.5 \mathrm{GPa}$. 
In this study, we aimed to fabricate silk resins using an easier method than the pulsed electric current sintering method. The raw silk powder was prepared from silk threads, which are normally wasted by crushing rather than by scouring and dissolving, as is traditionally done for this purpose. Two types of silk threads are investigated: silk from the Vietnamese domesticated B. mori silkworm and silk from the Samia cynthia ricini (or Eri) silkworm. Resins were prepared by hot pressing followed by drying. The mechanical properties of the resins were characterized. Specifically, the effects of drying after hot pressing on the three-point bending strength, micro-Vickers hardness, elastic modulus, water content, and apparent specific density of each resin were investigated. Moreover, X-ray diffraction (XRD), Fourier-transform infrared (FT-IR) spectroscopy, and high-performance liquid chromatography were used to explain the effects of the resinification and drying processes in terms of the structural characteristics.

\section{Materials and methods}

Figure 1 shows a flowchart describing the process used to prepare the silk resins. Eri silk thread and B. mori silk threads were milled and sieved to obtain silk powders, which were then hot pressed and dried to obtain the silk resins. This process is described in detail as follows.

\subsection{Silk Powders}

Raw Eri silk thread and B. mori silk thread were collected before degumming by the Vietnam Sericulture Research Center and used as the raw material in this study. The Eri silk thread was 
sourced from the ethnic minority in Vietnam. To prepare the silk powders, the Eri and B. mori silk threads were crushed using a planetary ball mill (Pulverisette 6, Fritsch, Germany) with a 500-mL alumina pot and $\varphi 15$ and $\varphi 20 \mathrm{~mm}$ alumina balls with a total weight of $3.2 \mathrm{~kg}$. The crushed silk powders had fiber lengths in the range of $1-3 \mathrm{~mm}$. Then, $2 \mathrm{~g}$ of the $3.2-\mathrm{kg}$ crushed power sample was milled at a rotational speed of $300 \mathrm{rpm}$ for 15 cycles, each including $1 \mathrm{~min}$ of milling time, $5 \mathrm{~min}$ of waiting time, and $1 \mathrm{~min}$ of reverse rotation. The milled silk powders were then sieved in a vibratory sieve shaker (AS200, Retsch, Germany) at 60 beats per minute for 60 min to obtain a silk powder with particles smaller than $50 \mu \mathrm{m}$. The mean particle sizes of the silk powders were confirmed by a laser diffraction particle size analyzer (SALD2300, SHIMADZU, Japan).

\subsection{Resinification}

Silk powder was loaded into a stainless steel die with the diameter of $20 \mathrm{~mm}$ for compaction by a hot press (H300-05, AS One, Japan) until the temperature reached a predetermined temperature (called the resinification temperature); the assembly was then allowed to cool. Because the mechanical properties were found to be consistent in the pressure range from 20 to $40 \mathrm{MPa}$, 31.2 $\mathrm{MPa}$ was chosen as the pressure for the resinification process. Several resinification temperatures in the range of $150{ }^{\circ} \mathrm{C}-180^{\circ} \mathrm{C}$ were tested. The samples were dried at $100{ }^{\circ} \mathrm{C}$ in a vacuum for different lengths of time from 3 to 7 days.

\subsection{Three-Point Bending Test and Micro-Vickers Hardness Test}

Small plate-shaped test pieces of $3 \mathrm{~mm}$ in width, $12 \mathrm{~mm}$ in length, and $2.5 \mathrm{~mm}$ in thickness were 
cut from the compacted silk resin samples. Three-point bending tests were conducted on a universal tensile testing machine (Autograph AGS-X series, SHIMADZU, Japan) with a support interval of $10 \mathrm{~mm}$ and a testing speed of $0.5 \mathrm{~mm} / \mathrm{min}^{-1}$. The maximum strength before failure was measured three times, and the average result was considered herein. The bending elastic moduli of the samples were calculated from their stress-strain curves. The hardness of each resin section was measured using a micro-Vickers hardness meter (HMV-G series, SHIMADZU, Japan), and the following equation was used to convert the results from Vickers Hardness (Hv) units to the SI units $(\mathrm{MPa}): \mathrm{MPa}=9.80 \times \mathrm{Hv}$.

\subsection{Structural Analysis}

The water contents in the silk powders and resins were measured by Karl Fischer titration ( 860 KF Thermoprep, Metrohm AG, Herisau, Switzerland). The apparent densities of the samples were measured by the Archimedes method using an analytical balance (AUX120, SHIMADZU Co., Japan). The structure of the resin was characterized in small cut samples of $10 \times 10 \mathrm{~mm}$ using XRD

(Ultimat IV, Rigaku Corp., Japan) and FT-IR spectroscopy (FT-IR-6600, Jasco Corp., Japan). The XRD was conducted using a $\mathrm{CuK} \alpha$ ray with tube conditions of $40 \mathrm{kV}$ and $40 \mathrm{~mA}$. The fractured resin sections from the three-point bending tests were observed using scanning electron microscopy (SEM) (JSM-6610LA, JEOL Ltd., Tokyo, Japan). 


\subsection{Amino Acid Analysis}

To characterize the amino acids in the fibroin samples, it was first necessary to hydrolyze the peptide bonds in the silk fibroin powders and resins using a 4-mol/L methanesulfonic acid solution. Then, an automated amino acid analysis was conducted with $0.2 \mathrm{wt} \%$ 3-(2-Aminoethyl) indole (Wako Pure Chemical, Japan) as the acid catalyst at $110^{\circ} \mathrm{C}$ for $24 \mathrm{~h}$ using a high-speed amino acid analyzer (AL-8800, Hitachi, Japan).

\section{Results and Discussion}

\subsection{Resinification and Densification}

Figure 2 shows the particle distributions in the silk powder after the sieving process. The columns represent the frequencies of the particle sizes $(\%)$, and the lines represent the integration of this distribution (\%) in the silk powder. Figure 3 (a) and (b) shows SEM images of the powders after sieving. The most frequent particle size in the distribution was around $60 \mu \mathrm{m}$ in both silk powders; other peaks were observed at 1 and $0.5 \mu \mathrm{m}$ in the particle size distributions for the Eri and $B$. mori silk powders, respectively. It has been reported that the tensile strength (elastic modulus) and elongation for B. mori silk thread are 4.3-5.2 g/denier (84-121 g/denier) and $10.0 \%-23.4 \%$, respectively, whereas those for Eri silk thread are 1.9-3.5 g/denier (29-31 g/denier) and 24\%-27\%, respectively [8]. Thus, it has been hypothesized that further milling of the powder beyond particle sizes in the range of $60-70 \mu \mathrm{m}$ was prevented by the cushioning effect [9], which notably results in 
softening of the material. Figure 3 (c) and (d) shows the fracture surfaces of the $150-^{\circ} \mathrm{C}$ hot-pressed resin samples after the three-point bending test. The fracture surface of the Eri silk resin reveals the presence of micro-fibers inside the resin, which are expected to directly affect the apparent density and mechanical properties of the resin. However, the B. mori resin exhibits a typical brittle fracture surface.

Figure 4 shows the water content and the apparent density of the resins as functions of the resinification temperature during hot pressing. After hot pressing, the water content of the Eri silk resin was reduced dramatically from 12 mass $\%$ to about 7.7 mass $\%$ whereas that of $B$. mori silk also decreased (though less significantly) from 11.7 mass $\%$ to about 9.1 mass $\%$. It has been reported that $B$. mori silk powder undergoes partial dissolution in water at the time of resinification in the presence of high-temperature steam and is homogeneously resinified [6]. Since the silk powders used in this study contained sufficient water content to facilitate this process, the addition of water was not required. Moreover, the water content in the resin was found to be independent of the resinification temperature. However, the apparent density of the B. mori silk resin was greater than that of the Eri silk resin over the entire range of resinification temperatures tested.

As described in Figures 1 and 2, B. mori silk powder comprises finer particles than Eri silk powder; densification occurs because of the semi-fusion state that is formed in the presence of fine particles. In addition, the apparent density of the B. mori silk resin samples increased as the resinification temperature increased whereas that of the Eri silk resin decreased with increasing resinification temperature. In general, since it is easy to densify the sample such that its 
resinification temperature increases, a higher density, such as that of the B. mori silk resin, is desirable. However, in the Eri silk resin, some of the water required to maintain a semi-molten state evaporated during a hot-pressing process due to the coarse particle size of the Eri silk powder and the remaining micro-fibers; overall, it was concluded that the resin from Eri silk did not exhibit sufficient densification. Moreover, because of the intense evaporation of moisture causing a moisture shortage in the samples treated with higher resinification temperatures, the resin densification was also considered insufficient in these samples.

Figure 5 shows the water contents and apparent densities of the resins as functions of the drying time when the resinification temperature was fixed to $150^{\circ} \mathrm{C}$. In both resins, the water content decreased with longer drying times, falling as low as $0.5 \mathrm{wt} \%$ by day 7 . Moreover, the water content in the Eri silk resin with low density and insufficient densification decreased more quickly than in the $B$. mori silk resin. This was attributed to the formation of pores in the Eri silk resin that allows water to pass through the structure.

\subsection{Mechanical Properties of Resins}

Figure 6 shows the relationship between the mechanical properties of the silk resins that were hot pressed at $150{ }^{\circ} \mathrm{C}$ as functions of the drying time. The data show that the longer the drying time was, the more the micro-Vickers hardness, three-point bending strength, and elastic modulus of the resin increased. Moreover, the mechanical properties of the Eri silk resin were inferior to those of the B. mori silk resin at all drying temperatures. Specifically, the B. mori and Eri silk resins exposed to the longest drying time of 7 days had the highest mechanical properties: three-point bending 
strengths of 112 and $98 \mathrm{MPa}$, respectively, elastic moduli of 9.1 and $8.5 \mathrm{GPa}$, respectively, and micro-Vickers hardness values of $\mathrm{Hv} 60$ and $\mathrm{Hv} 55$, respectively. These mechanical properties represent significant improvements over those attained in previous studies [4-6,10]. These excellent mechanical properties of $B$. mori silk resin were attributed to the higher apparent density of $B$. mori silk resin compared with Eri silk resin. Thus, the mechanical properties of the resins are considered to depend on their densification and resinification transformation.

\subsection{Structural Analysis}

The XRD spectra obtained from the silk powders and silk resins fabricated at a constant temperature of $150^{\circ} \mathrm{C}$ are shown in Figure 7. Both spectra show amorphic phasess [11], [12] and present and demonstrate the formation of crystalline phases [12]. The crystal structure of the Eri silk II was characterized by peaks at $16.4^{\circ}, 19.3^{\circ}$, and $23.8^{\circ}$, whereas the $B$. mori silk II exhibited peaks at $18.0^{\circ}, 20.2^{\circ}$, and $24.0^{\circ}$ [13]. The differences between these diffraction peaks were attributed to the differences in the unit cell dimensions in these materials [14]. The intensities of the crystal peaks were increased after drying for 7 days in parallel with the increase in the mechanical properties. This is considered to be because the residual water leaving the resins was in the bound water form. During this process, the secondary structure of the resin was pleated from small stacked $\beta$-pleated-sheet crystal to bigger stacked $\beta$-pleated-sheet crystal [15]. These findings are consistent with previous reports, demonstrating that water impacts the strength of a crystallite structure as it reduces the number of hydrogen bonds, the hydrogen bond lifetime, and the peak rupture force and increases the specific interaction energy [16]. This also explains why the mechanical properties of 
resins were increased after the drying process.

Figure 8 shows the FT-IR spectra, which indicate that the changes in the fibroin's secondary structure after the hot pressing and drying. The secondary derivatives that can be used to characterize the secondary structure of Amide I are shown in Figure 9. It has been reported that Eri silk without sericin exhibits absorption bands at $1649 \mathrm{~cm}^{-1}$ (amide I), 1559 and $1523 \mathrm{~cm}^{-1}$ (amide II), and $1233 \mathrm{~cm}^{-1}$ (amide III). On the other hand, B. mori silk fibers without sericin showed intense absorption bands at $1643 \mathrm{~cm}^{-1}$ (amide I), $1509 \mathrm{~cm}^{-1}$ (amide II), and $1127 \mathrm{~cm}^{-1}$ (amide III) [17]. In the obtained secondary derivatives, the absorption peaks at $1633 \mathrm{~cm}^{-1}$ (amide I), $1515 \mathrm{~cm}^{-1}$ (amide II), and $1233 \mathrm{~cm}^{-1}$ (amide III) were attributed to the formation of a $\beta$-sheet structure in the fibroin of the Eri silk powder. The peaks at $1641 \mathrm{~cm}^{-1}$ (amide I) were indicative of a random coil structure, and those at $1515 \mathrm{~cm}^{-1}$ (amide II) and $1231 \mathrm{~cm}^{-1}$ (amide III) were indicative of a $\beta$-sheet structure in the B. mori silk powder. In the spectra of the Eri silk resin, the peaks in the amide I and amide III bands shifted to lower wavenumbers simultaneously. In the spectra of B. mori silk resin, the peaks of the amide I band shifted to a lower wavenumber, whereas the peaks of the amide II and amide III bands did not change. Thus, it was concluded that the secondary structure of the resins did not change significantly upon removal of the water by drying.

On the basis of the secondary derivatives method used previously [18], the component peaks were identified via the curve fitting process as shown in Figure 9. In a previous study [19], it was reported that the $\beta$-sheet structure is characterized by a strong absorption peak at $1633.41 \mathrm{~cm}^{-1}$ and a relatively weak peak at $1698.02 \mathrm{~cm}^{-1}$ and the random coil structure is characterized by absorption 
peaks at 1644.98 and $1651.73 \mathrm{~cm}^{-1}$; moreover, absorption peaks at $1668.12,1673.91,1681.62$, and $1688.37 \mathrm{~cm}^{-1}$ are indicative of a $\beta$-turn structure, peaks at 1604.48 and $1611.23 \mathrm{~cm}^{-1}$ represent a side chain structure, a peak at $1618 \mathrm{~cm}^{-1}$ indicates a $\beta$-strand structure, and a peak at $1660.41 \mathrm{~cm}^{-1}$ represents an $\alpha$-helix structure.

Table 1 shows the amide I components determined on the basis of the secondary derivatives in Figure 8 . The $\beta$-sheet structure in the $B$. mori silk increased while the random coil structure decreased after resinification and drying. This means that the secondary structure of the $B$. mori silk was converted from a random coil structure to a $\beta$-sheet structure. Meanwhile, the secondary structure of the Eri silk resin was converted from a random coil structure to a $\beta$-strand structure upon resinification process and the $\beta$-strand structure transitioned into a $\beta$-sheet structure upon drying. It is well known that presence of a $\beta$-sheet structure influences the bending properties of the material [16]. As there are no differences between the $\beta$-sheet structure contents in Eri and B. mori silk resins after the resinification and drying, it is clear that observed differences in their bending properties are to the density differences.

Table 2 shows the amino acid compositions of silk powders and silk resins. The amino acids composition was unchanged upon resinification in both resins. The main amino acids in the $B$. mori silk included glycine and serine, which are hydrophilic amino acids; these were more abundant in the B. mori silk than in the Eri silk. Accordingly, the ratio of hydrophobic amino acids to hydrophilic amino acids was higher in the Eri silk resin than in the B. mori silk resin. Because the B. mori silk powder contains a large proportion of hydrophilic amino acids and has fewer 
hydrophobic $\beta$-sheet structures, it exhibits strong hydrophilic properties. Thus, it is assumed that the hydrophilic amino acids in the B. mori silk contribute to the higher apparent density of the resin.

\section{Conclusions}

The highest three-point bending strength of $112 \mathrm{MPa}$ and the highest elastic modulus of $9.1 \mathrm{GPa}$ were obtained in the $B$. mori resin that was prepared by hot pressing the raw silk powder at $150{ }^{\circ} \mathrm{C}$. These values were higher than those in the resins that were prepared by a pulsed electric current sintering method with refined silk. The B. mori silk resins exhibited higher apparent densities, bending strengths, and micro-Vickers hardness values compared with the Eri silk resins. On the basis of the FT-IR spectra of B. mori silk, the $\beta$-sheet structure was formed while the random coil structure was broken down upon resinification and drying. On the other hand, the secondary structure of the Eri silk resin was converted from a random coil structure to a $\beta$-strand structure upon resinification and $\beta$-strand structure was converted to a $\beta$-sheet structure upon drying. However, because there was no difference between the $\beta$-sheet structure contents in the Eri and B. mori silk resins after resinification and drying, it can be concluded that the observed differences in the bending properties are related to the density of the resin.

\section{Acknowledgment}

This work was supported by Super High-Function Structure Proteins to Transform the Basic Materials Industry of ImPACT (Impulsing Paradigm Change through Disruptive Technologies 
Program), Japan. 


\section{References}

[1] FAO, "FAOSTAT_data_3-8-2018 (Livestock Primary),” 2018.

[2] N.Sakthivel, "Evaluation of Cassava Varieties for Eri Silkworm , Samia Cynthia Ricini," Mun. Ent. Zool., vol. 11, no. March, pp. 165-168, 2016.

[3] S.Prasong, S.Wilaiwan, and S.Yaowalak, "Cross-section images of Eri (Samia ricini) - silk fibers and their secondary structures after treatment with different organic solvents," J. Biol. Sci., vol. 11, no. 1, pp. 46-51, 2011.

[4] J.Hosokawa, T.Endo, M.Nishiyama, T.Morita, and M.Funahashi, "Development of Turtleshell-Work-Materials Using Silk Protein - Thermal and Mechanical Properties of Turtleshell and Hotpressed Fibroin,” Kobunshi Ronbunshu, vol. 50, no. 12, pp. 929-934, 1993.

[5] J.Hosokawa, T.Endo, R.Kitagawa, and A. M.Nishiyama, "Properties of novel ornamental material boards made from silk fibroin sheet," J. Chem. Eng. Japan, vol. 29, no. 6, pp. 10571059, 1996

[6] A.Kaneko, Y.Tamada, S.Hirai, T.Kuzuya, and A. T.Hashimoto, "Characterization of a Silk-Resinified Compact Fabricated Using a Pulse-Energizing Sintering Device,” pp. 272$278,2012$.

[7] “Japan Patent JP.04-029766.B."

[8] B.Kundu, R.Rajkhowa, S.Kundu, and X.Wang, "Silk fibroin biomaterials for tissue regenerations," Adv. Drug Deliv. Rev., vol. 65, no. 4, pp. 457-470, 2013. 
[9] M.Kazemimostaghim, R.Rajkhowa, K.Patil, T.Tsuzuki, and X.Wang, "Structure and characteristics of milled silk particles," Powder Technol., vol. 254, pp. 488-493, 2014.

[10] W.Yu, T.Kuzuya, S.Hirai, and Y.Tamada, "Fabrication of Silk Resin Sheets Using a Hot-Rolling Equipment Division of Engineering for Composite Functions," Sen'i Gakkaishi, vol. 60, pp. 259-264, 2012.

[11] G.M.Nogueira et al., "Preparation and characterization of ethanol-treated silk fibroin dense membranes for biomaterials application using waste silk fibers as raw material," Bioresour. Technol., vol. 101, no. 21, pp. 8446-8451, 2010.

[12] M. Kazemimostaghim, R. Rajkhowa, and X. Wang, "Comparison of milling and solution approach for production of silk particles," Powder Technol., vol. 262, pp. 156-161, 2014.

[13] S.Dutta, B.Talukdar, R.Bharali, R.Rajkhowa, and D.Devi, "Fabrication and Characterization of Biomaterial Film from Gland Silk,” Biopolymers, vol. 99, no. 5, pp. 326-333, 2012.

[14] J.O.Warwicker, “Comparative studies of fibroins," J. Mol. Biol., vol. 2, no. 6, pp. 350-362, 1960.

[15] X.Hu, D.Kaplan, and P.Cebe, "Dynamic Protein and Water Relationships during b-Sheet Formation," Macromolecules, vol. 41, pp. 3939-3948, 2008.

[16] Y.Cheng, L.-D.Koh, D.Li, B.Ji, M.-Y.Han, and Y.-W.Zhang, "On the strength of $\beta$-sheet crystallites of Bombyx mori silk fibroin,” J. R. Soc. Interface, vol. 11, no. 96, 2014.

[17] S.Prasong, S.Yaowalak, and S.Wilaiwan, "Characteristics of silk fiber with and without sericin component a comparision between Bombyx mori.pdf," Pakistan J. Biol. Sci., vol. 12, 
no. 11, pp. 872-876, 2009.

[18] H.Susi and D.M.Byler, "Protein structure by Fourier transform infrared spectroscopy: Second derivative spectra,” Biochem. Biophys. Res. Commun., vol. 115, no. 1, pp. 391-397, 1983.

[19] X.Hu, D.Kaplan, and P.Cebe, "Determining beta-sheet crystallinity in fibrous proteins by thermal analysis and infrared spectroscopy," Macromolecules, vol. 39, no. 18, pp. 6161-6170, 2006. 


\section{Biography of Author}

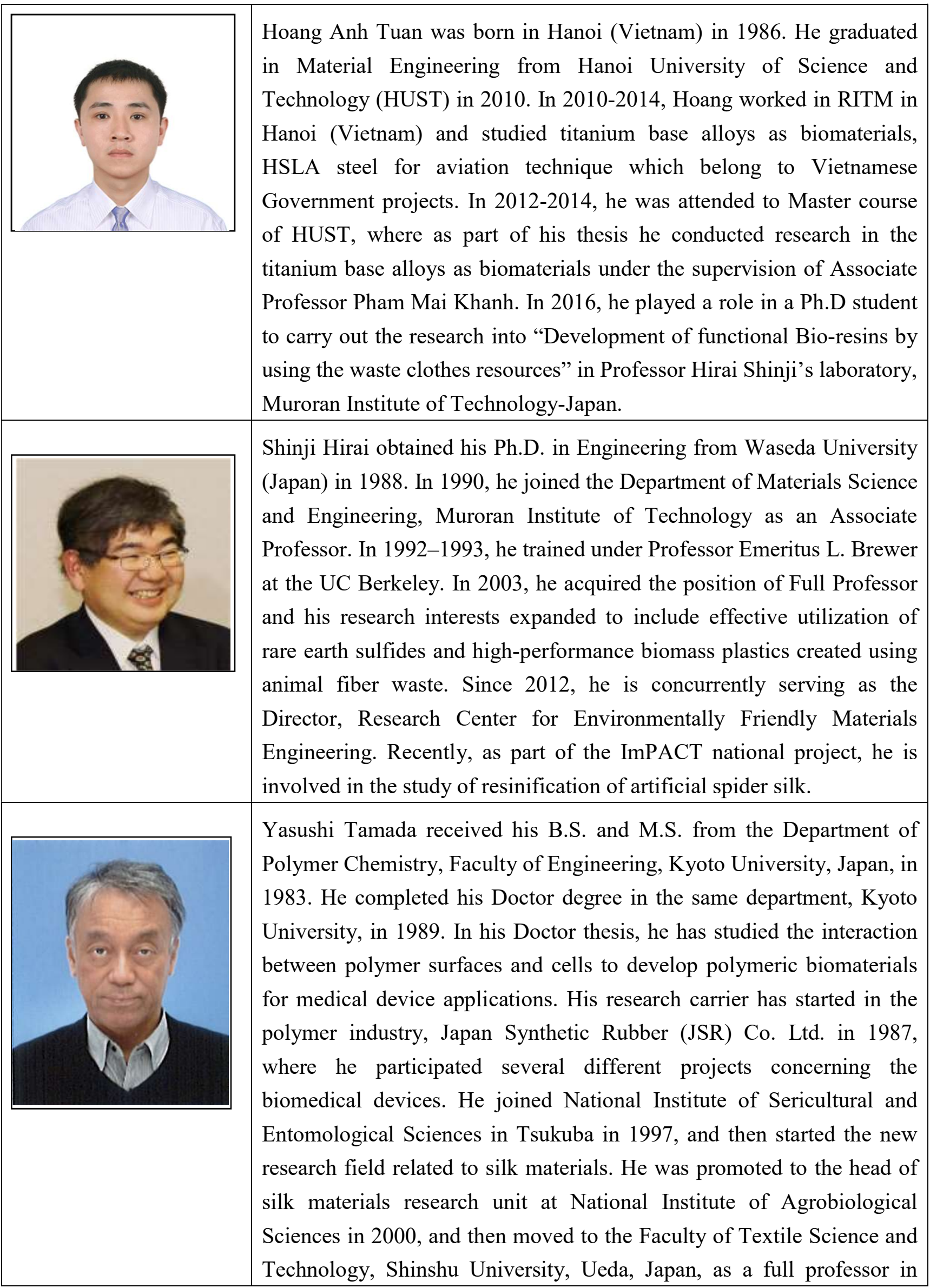




\begin{tabular}{|l|l|}
\hline & $\begin{array}{l}\text { 2013. He was awarded the prize of the Japanese Society of Silk Science } \\
\text { in 2012. }\end{array}$ \\
\hline & $\begin{array}{l}\text { Shota Akioka was born in Sapporo, Hokkaido (Japan) in 1991. He } \\
\text { graduated from Muroran Institute of Technology in } 2014 \text { and master } \\
\text { course of there in } 2016 \text { under supervising of Professor Hirai Shinji. He } \\
\text { carried out the research for fabrication of material using protein } \\
\text { "fibroin" including silk in 2013-2016. In 2016-2017, he studied about } \\
\text { Bio-materials as structural material in a company involved participating } \\
\text { in the national project. From 2018 until now, he continues researching } \\
\text { the materials using animal's protein as the doctor's student of Muroran } \\
\text { Institute of Technology. }\end{array}$ \\
\hline
\end{tabular}




\section{Highlights}

1. The highest mechanical properties of B. mori resin were $112 \mathrm{MPa}$ and $9.1 \mathrm{GPa}$ for three-points bending and Young's Modulus, respectively, prepared by hot pressing at $150{ }^{\circ} \mathrm{C}$.

2. This kind of resins were higher than those resins made by a pulsed electric current sintering method with refined silk.

3. The secondary structure of silk fibroin was converted from random coil to $\beta$-sheet after the resinification process.

4. The mechanical properties of the resins are considered to depend on their densification and resinification transformation. 


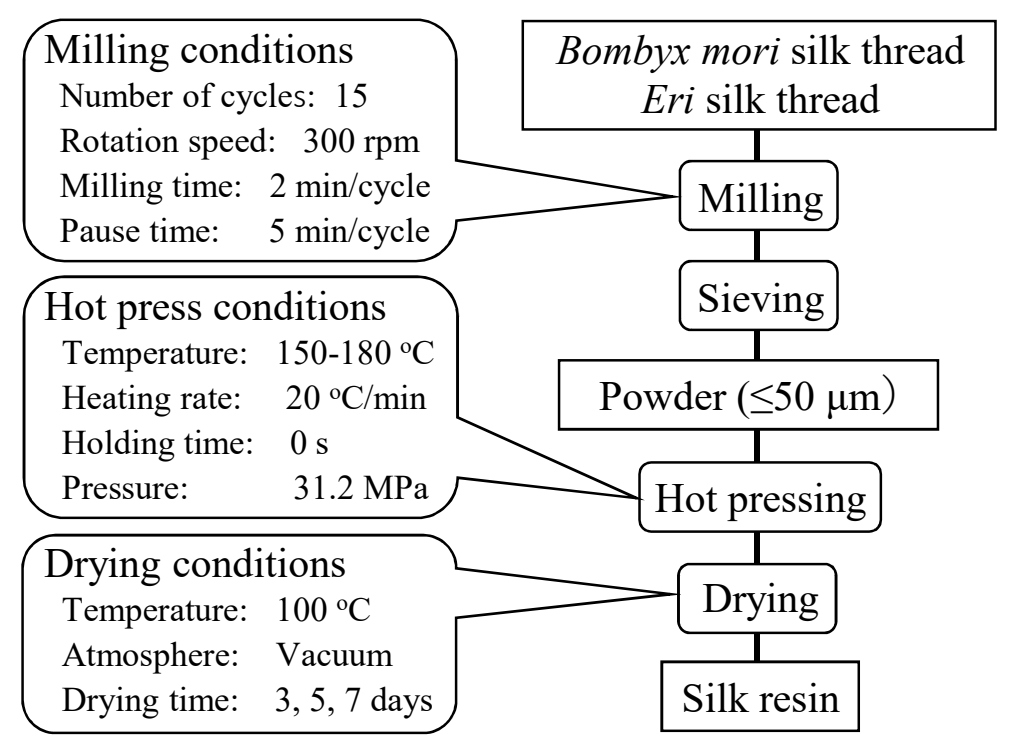

Figure 1 Process of preparing silk resins.

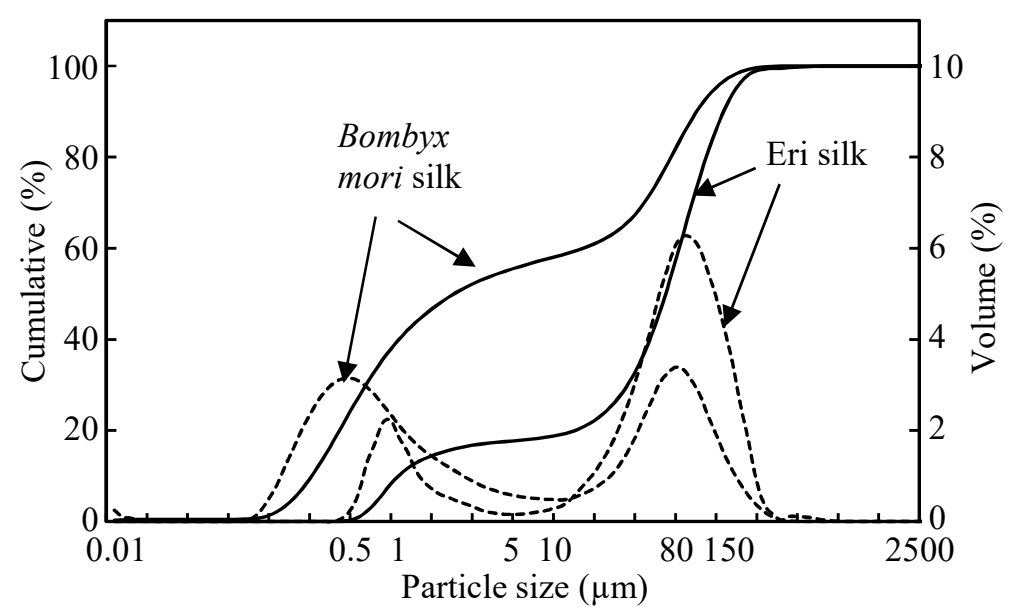

Figure 2 Particle-size distributions in the silk powders after sieving. The solid lines represent the cumulative volume distributions and the dotted lines represent the particle volume distributions. 


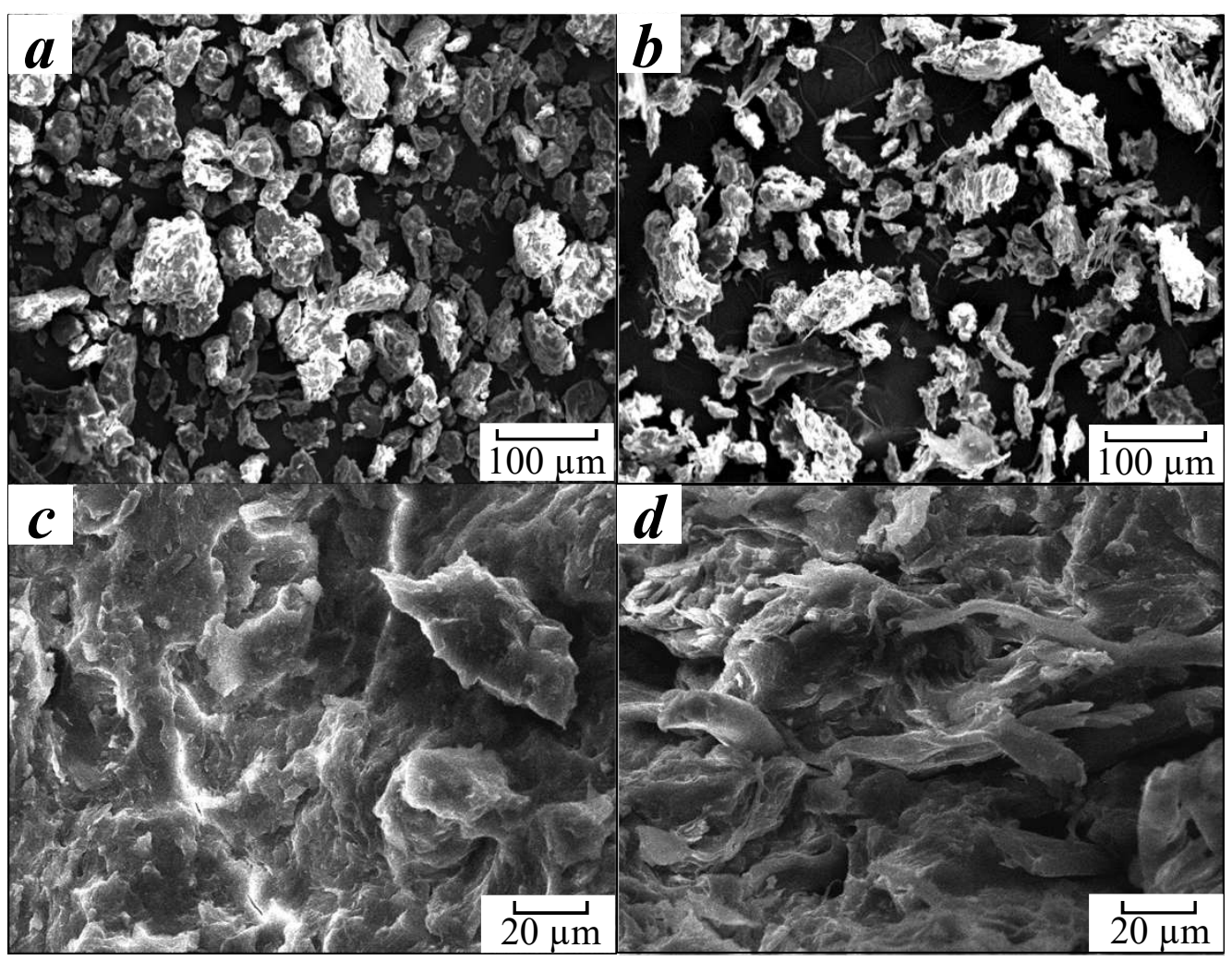

Figure 3 SEM images of (a) the Bombyx mori silk powder and (b) the Eri silk powder after sieving and the fracture surfaces of (c) the B. mori silk resin and (d) the Eri silk resin. 


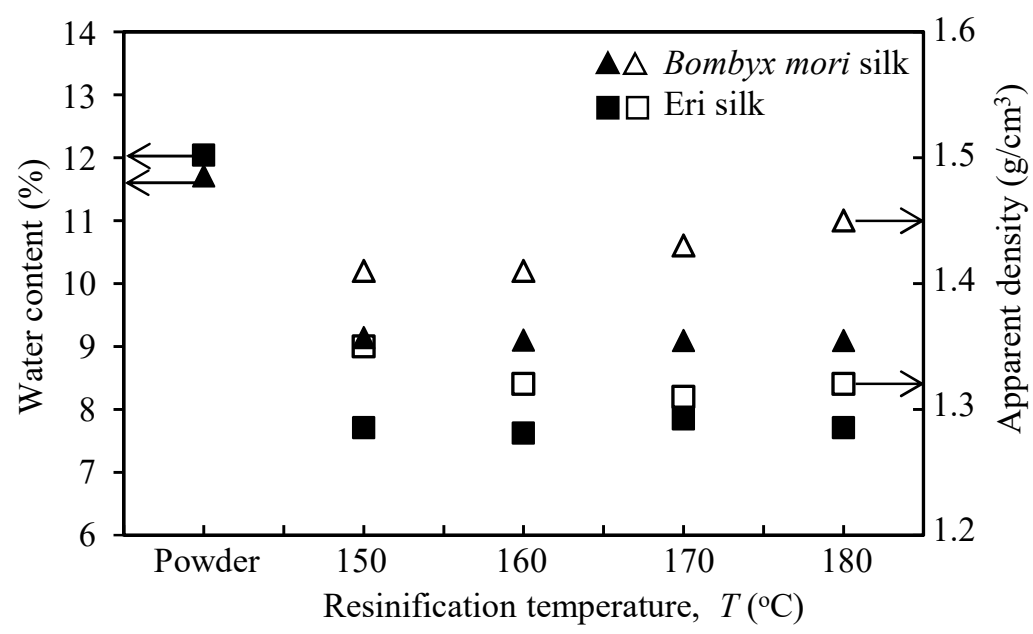

Figure 4 Water content and apparent density of the two resins as functions of the resinification temperature during hot pressing.

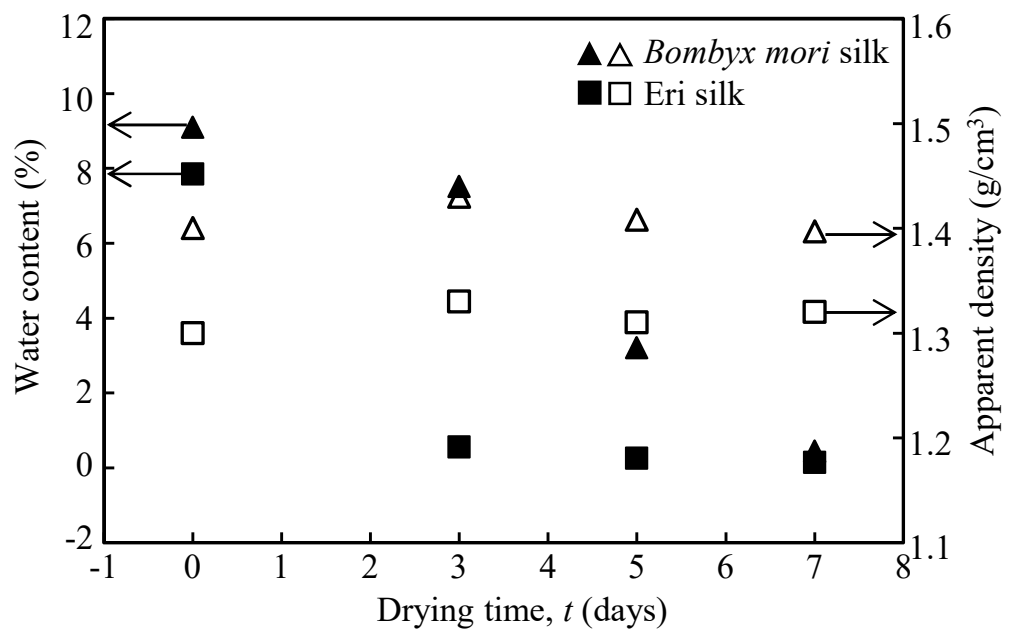

Figure 5 Drying time dependences on the water content and apparent density of resins when a resinification temperature is fixed to $150{ }^{\circ} \mathrm{C}$ under a pressure of $20 \mathrm{MPa}$. 

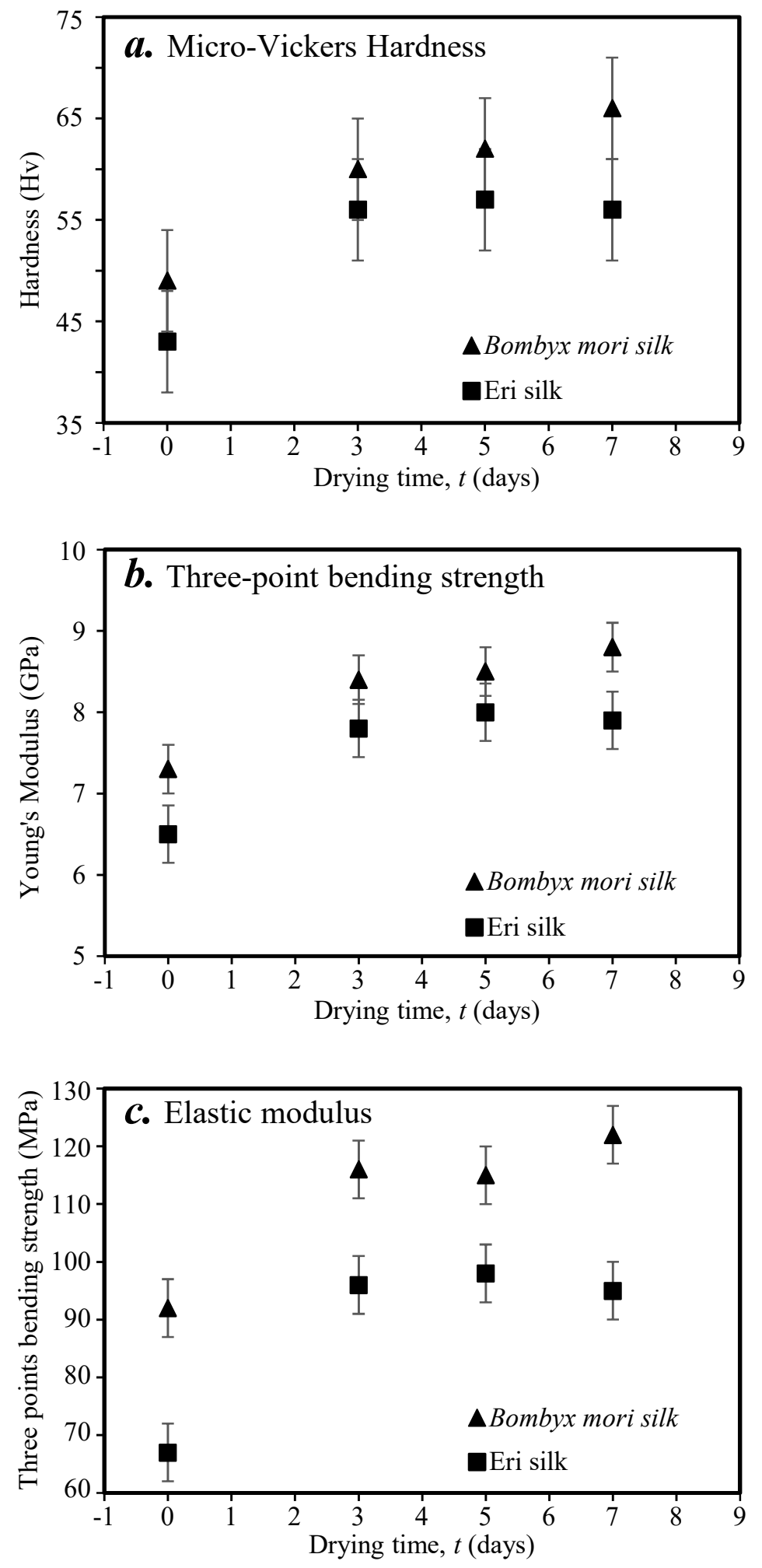

Figure 6 Relationships between the mechanical properties and the drying time for the silk resins that were hot-pressed at a $150{ }^{\circ} \mathrm{C}$. 


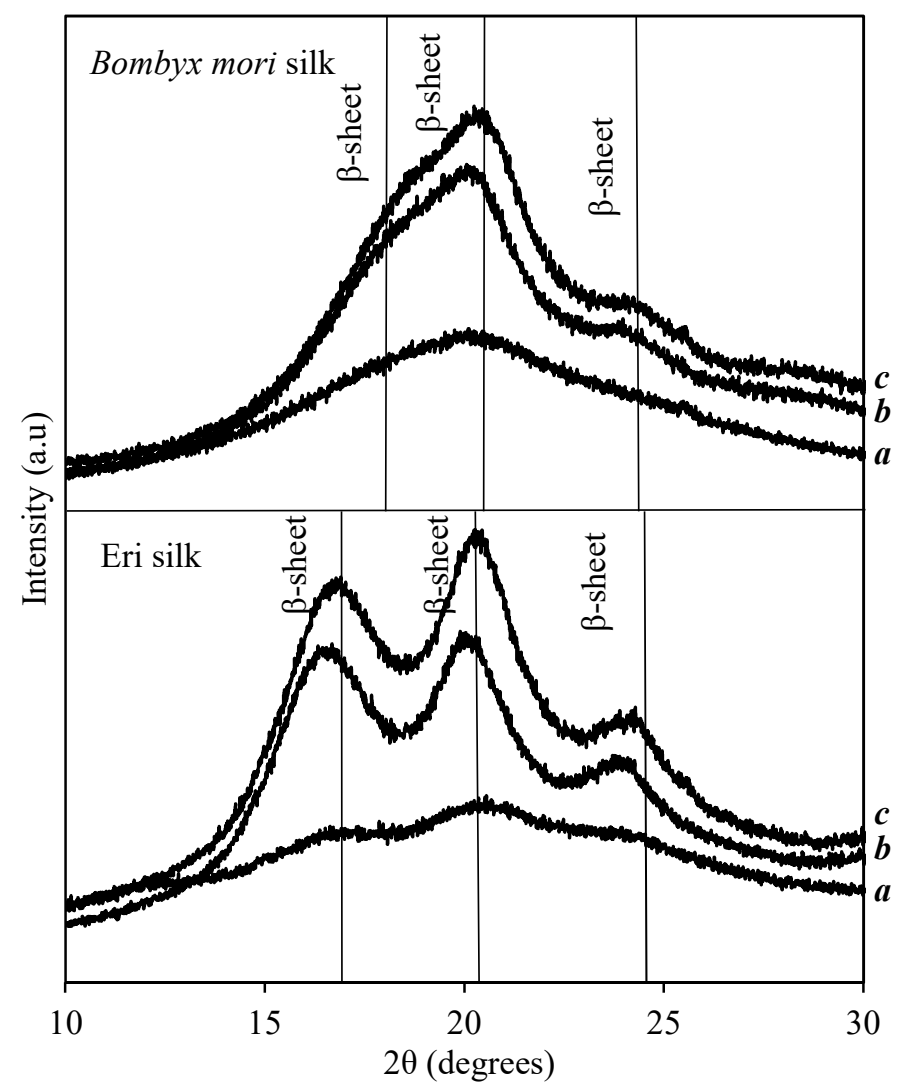

Figure 7 XRD spectra of (a) the silk powders, (b) the resins, and (c) the resin after drying for 7 days when the resinification temperature was fixed at $150{ }^{\circ} \mathrm{C}$ with a pressure of $20 \mathrm{Mpa}$. 


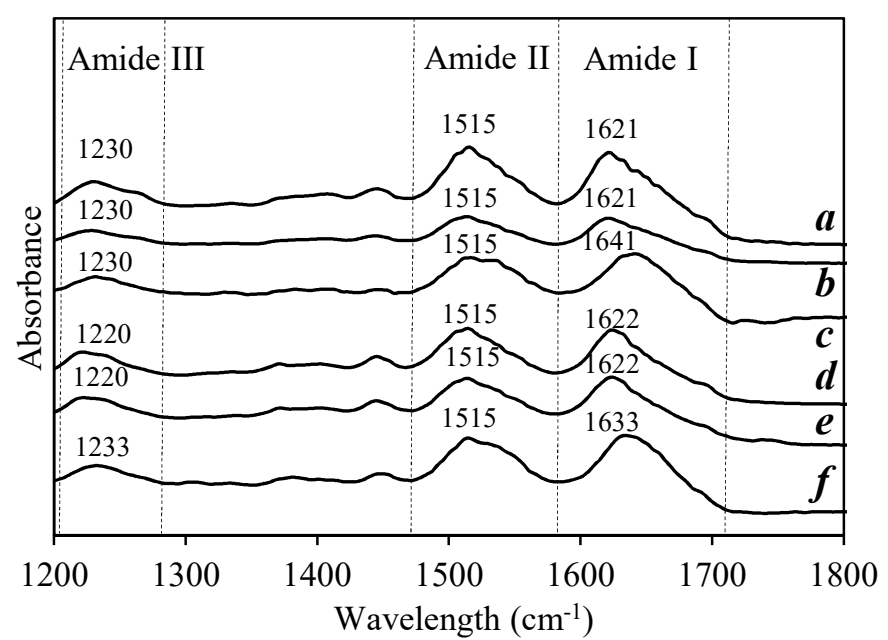

Figure 8 FT-IR spectra of the silk powders and resins when the resinification temperature was fixed to $150{ }^{\circ} \mathrm{C}$ with a pressure of $20 \mathrm{MPa}$ : (a) Bombyx mori silk powder, (b) Bombyx mori silk resin, (c) Bombyx mori silk resin after drying for 7 days, (d) Eri silk powder, (e) Eri silk resin, and (f) Eri silk resin after drying for 7 days.

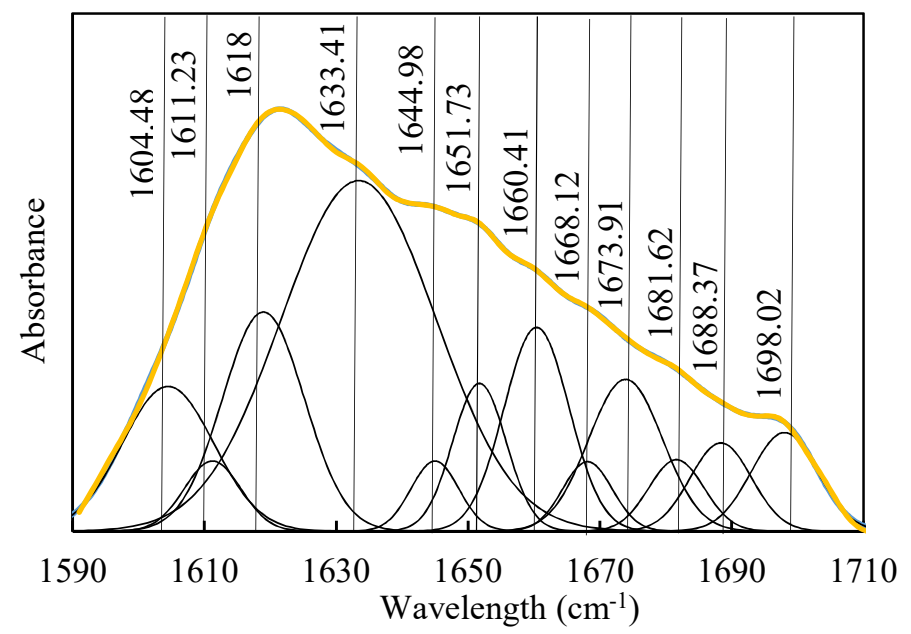

Figure 9 Curve fitting to the FT-IR spectra by using the secondary derivatives to determine the secondary of amide I. 


\section{Table Legends}

Table 1 The secondary structure content (\%) of Amide I of Bombyx mori silk and Eri silk

\begin{tabular}{llllllll}
\hline \multirow{2}{*}{ Assignment } & $\alpha$ & $\beta$ & $\beta$ & RC & $\beta$ & SC \\
& & helix & strand & sheet & & turn & \\
\hline \multirow{2}{*}{$\begin{array}{l}\text { Bombyx } \\
\text { mori } \\
\text { silk }\end{array}$} & Powder & 21.7 & 4.5 & 25.4 & 22.0 & 18.5 & 7.9 \\
& Resin & 5.1 & 4.3 & 36.6 & 12.4 & 18.9 & 22.7 \\
& Resin & 9.2 & 12.4 & 42.1 & 7.8 & 16.7 & 11.8 \\
& dried & & & & & & \\
\multirow{5}{*}{ Eri silk } & Powder & 12.9 & 4.6 & 34.8 & 19.5 & 21.1 & 7.1 \\
& $\begin{array}{l}\text { Resin } \\
\text { Resin }\end{array}$ & 8.8 & 11.6 & 34.2 & 9.2 & 15.9 & 20.3 \\
& dried & 6.3 & 7.4 & 44.9 & 16.9 & 17.1 & 7.5 \\
\hline
\end{tabular}

Table 2 Amino acids composition of Bombyx mori silk and Eri silk powder and resins

\begin{tabular}{|c|c|c|c|c|c|}
\hline \multirow{2}{*}{\multicolumn{2}{|c|}{ Amino Acids }} & \multicolumn{2}{|c|}{ Bombyx mori silk } & \multicolumn{2}{|c|}{ Eri silk } \\
\hline & & Powder & Resin & Powder & Resin \\
\hline \multirow{10}{*}{ 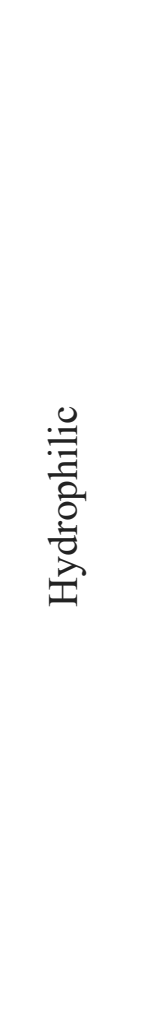 } & Pro & 0.56 & 0.56 & 0.41 & 0.42 \\
\hline & Gly & 38.64 & 38.50 & 31.24 & 31.44 \\
\hline & Ser & 14.56 & 14.48 & 6.97 & 6.98 \\
\hline & Glu & 1.91 & 1.92 & 0.92 & 0.92 \\
\hline & Asp & 4.78 & 4.81 & 4.12 & 4.12 \\
\hline & Cys & 0.20 & 0.17 & 0.09 & 0.08 \\
\hline & Thr & 2.55 & 2.55 & 0.51 & 0.52 \\
\hline & Lys & 0.84 & 0.79 & 0.26 & 0.27 \\
\hline & His & 0.49 & 0.47 & 1.26 & 1.26 \\
\hline & Arg & 1.07 & 1.07 & 1.98 & 1.97 \\
\hline \multirow{2}{*}{ 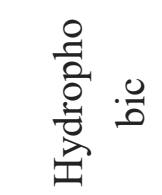 } & Ala & 25.21 & 25.30 & 45.17 & 44.75 \\
\hline & Met & 0.07 & 0.08 & 0.01 & 0.01 \\
\hline
\end{tabular}




\begin{tabular}{ccccc}
\multicolumn{1}{c}{ Val } & 2.60 & 2.62 & 0.61 & 0.60 \\
Phe & 0.68 & 0.67 & 0.23 & 0.23 \\
Ile & 0.69 & 0.69 & 0.38 & 0.38 \\
Leu & 0.68 & 0.68 & 0.37 & 0.37 \\
$\quad$ Tyr & 4.45 & 4.59 & 5.42 & 5.63 \\
$\begin{array}{l}\text { Hydrophobic/hy-drophilic } \\
\text { ratio }\end{array}$ & 2.23 & 2.23 & 3.64 & 3.59 \\
Basic amino acid (mol\%) & 2.4 & 2.33 & 3.5 & 3.5 \\
Acidic amino acid (mol\%) & 6.69 & 6.73 & 5.04 & 5.04 \\
Basic/acidic ratio & 0.36 & 0.35 & 0.69 & 0.69 \\
\hline
\end{tabular}

